\title{
Biochemical and chemical characterization of Cynara cardunculus $L$. extract and its potential use as co-adjuvant therapy of chronic myeloid leukemia
}

\author{
Antonio Russo ${ }^{1}$, Mariarita Perri ${ }^{1}$, Erika Cione ${ }^{1}$, Maria Luisa Di Gioia, Monica Nardi, \\ Maria Cristina Caroleo* \\ Department of Pharmacy Health and Nutritional Sciences, University of Calabria, Via Savinio, Arcavacata di Rende, 87036 Cosenza, Italy
}

\section{A R T I C L E I N F O}

Keywords:

$\mathrm{P} 210^{\mathrm{BCR} / \mathrm{ABL}}$ oncoprotein

Cynara cardunculus L.

K562 cells

Imatinib resistant

Chronic myeloid leukemia

\begin{abstract}
A B S T R A C T
Ethnopharmacological relevance: Ancient mediterranean diet was characterized by consuming the spontaneous forms of Cynara cardunculus L. (CCL), commonly called artichoke. Cultivated and/or spontaneous forms of CC studies have demonstrated that methanol extract of CCL flower and/or cynaropicrin showed remarkable anti-proliferative activity in vitro models of leukocyte cancer cell.

Aim of the study: Chronic myeloid leukemia (CML) is associated with a reciprocal translocation of the long arms of chromosomes 9 and 22 generating the $B C R / A B L$ fusion gene, translated in the $\mathrm{p} 210^{\mathrm{BCR} / \mathrm{ABL}}$ oncoprotein kinase. This chimeric protein is the target of a kinase inhibitor, imatinib, but the development of mutations in the ABL kinase domain resulting in drug resistance and several approaches to overcoming resistance have been study. In this concern, we investigated the effect of CCL extract on human K562 CML and K562 imatinib resistant (IMAR) cell proliferation and on p210 $\mathrm{BCR} / \mathrm{ABL}$ expression.

Materials and methods: Chemical characterization of the CCL extracts was performed by GC/MS analysis and semipreparative RP-HPLC chromatography. Structural characterization of compounds was assessed by ${ }^{1} \mathrm{H}-{ }^{13} \mathrm{C}$ NMR and LC/MS analysis. The effects of CCL extracts on the proliferation of K562 CML human cell line and K562 IMAR were screened by MTT assay. The p210 ${ }^{\mathrm{BCR} / \mathrm{ABL}} \mathrm{mRNA}$ and protein expressions were analyzed by qRT-PCR and Western blot techniques respectively.

Results: We demonstrate that CCL extract affect cell viability of both K562 CML human cell line and K562 IMAR. The biocomponents of CCL were chemical characterized and we identify cynaropicrin and its deacyl derivative having the capability to down-regulate the $\mathrm{p} 210^{\mathrm{BCR} / \mathrm{ABL}}$ oncoprotein.

Conclusions: Our study suggests that the use of those molecules could represent a novel and promising strategy to potentiate the ability of imatinib or of its analogues to induce cancer growth arrest in CML and to delay or overcome the resistance of CML to chemotherapy.
\end{abstract}

\section{Introduction}

Phytochemicals, which are non-nutritive compound present in dietary products such as fruit and plants, have emerged as modulators of key cellular signaling pathways (González-Vallinas et al., 2013). In this concern, it is well known the effect of bioactive components of Cynara cardunculus (CC) commonly called artichoke as choleretic hepatoprotective (increasing the bile flow) and hypocholesterolemic (lowering blood cholesterol rate). Both caffeoylquinic acid and flavonoids present in the cynara extracts are endowed with antioxidant activity, against free radicals and thus are effective in the prevention of severe coronary artery diseases, atherosclerosis, exerting also anticancer activity. In Italy $\mathrm{CC}$ has a distribution spanning from Tuscany to the southern areas, with a prevalent presence in Sicily, Basilicata and Calabria (Pignone and Sonnante, 2004). Ancient mediterranean diet was characterized by consuming the spontaneous forms of Cynara cardunculus L. (CCL). Cultivated and/or spontaneous forms of CC studies have demonstrated that methanol extract of CCL flower and/or cynaropicrin showed remarkable anti-proliferative activity in vitro models of leukocyte cancer cell (Cho et al., 2004). Among blood cancer, Chronic Myeloid Leukemia (CML) a clonal myeloproliferative disorder is most frequent in adult age, with an incidence of 1-2 cases per

\footnotetext{
* Corresponding author

E-mail address: mariacristinacaroleo@virgilio.it (M. Cristina Caroleo).

${ }^{1}$ equally contributed.
} 
100,000 adults. The disease arises from neoplastic transformation of the hematopoietic stem cell and is characterized by a genetic translocation, $t(9 ; 22)$ (q34;q11.2), involving a fusion of the Abelson oncogene (ABL) from chromosome 9q34 with the Breakpoint Cluster Region (BCR) gene on chromosome 22q11.2. This rearrangement is known as the Philadelphia chromosome. The molecular consequence of this translocation is the generation of a BCR-ABL fusion oncogene, which in turn translates into the $\mathrm{p} 210^{\mathrm{BCR} / \mathrm{ABL}}$ oncoprotein with tyrosin kinase activity. Expression and activity of $\mathrm{p} 210^{\mathrm{BCR} / \mathrm{ABL}}$ is necessary and sufficient for hematopoietic cell transformation and disease maintenance as demonstrated by in vitro assays and leukemogenesis in mice. BCR/ABL-dependent transformation of hematopoietic cells involves the assembly of multiprotein complexes and the phosphorylation of various substrates, which is essential to generate proliferative and antiapoptotic signals (Lahlou, 2013; Savage et al., 1997; Spiers, 1977; Nowell and Hungerford, 1960; Rowley, 1973; Ben-Neriah et al., 1986; McLaughlin et al., 1987; Daley and Baltimore, 1988; Daley et al., 1990). The chimeric protein the $\mathrm{p} 210^{\mathrm{BCR} / \mathrm{ABL}}$ is the target of tyrosine kinase inhibitors (TKIs) and among them imatinib was the major breakthrough in CML therapy (Moen et al., 2007), nevertheless recent data indicate the need for a new approach in the therapy of this disease (Cayssials and Guilhot, 2016; Trela et al., 2014). The classical in vitro model for studying CML is the K562 and the K562 imatinib resistant (IMAR) human cell lines. Using this methodological approach, we investigated the effect of CCL extract on cell proliferation and on $\mathrm{p} 210^{\mathrm{BCR} / \mathrm{ABL}}$ oncoprotein kinase expression. We found that CCL bioactive components from total extract affected cell viability in both cell lines. Therefore, the total extract was further divided into lipophilic and hydrophilic fractions evidencing that only the lipophilic ones displayed a strong cytotoxic effect. Through several analytical approaches, we detected in the lipophilic fraction different components and among them, cynaropicrin as the main sesquiterpene lactone and its deacyl derivative. Both molecules strongly inhibited cell proliferation and were able to induce the down regulation of $\mathrm{p} 210^{\mathrm{BCR} / \mathrm{ABL}}$ oncoprotein kinase in K562 and K562 IMAR cell lines. Our results suggest that cynaropicrin and its deacyl derivative could be a novel and promising tool in the therapeutic management of CML.

\section{Materials and methods}

\subsection{Preparation of methanolic extract of $C C L$}

Spontaneous forms of Cynara cardunculus L. (Asteraceae) were collected during the flowering stage, in June 2013, in a wild area between Cavoni-Ginestreto district (39 $26^{\prime} 49.239^{\prime \prime}$ N, $16^{\circ} 15^{\prime} 44.575^{\prime \prime}$ E) in Luzzi (Cosenza, Italy). The plant materials were authenticated by the authors, and preserved until extraction. The aerial parts of CCL (200 g) were air dried until dryness at room temperature, cut into small pieces and then extracted with a $70 \%$ methanol solution in water, through maceration ( $48 \mathrm{~h}$ for 3 times). The resultant total extracts (Te) were dried under reduced pressure and their weight was determined $(10.3 \mathrm{~g}, 5 \%$ yield $\mathrm{w} / \mathrm{w})$. The obtained extract was suspended in water and partitioned with hexane to give lipophilic (Le) (27\%) and hydrophilic fractions (He) (73\%).

\subsection{Derivatization and GC-MS analysis of extracts}

Each extract (Te, Le, He) was dissolved in acetonitrile. $1 \mathrm{ml}$ of N,Obis-trimethylsilylacetamide (BSA), trimethylchlorosilane (TMS- Cl) $1 \%$ /BSA and $0.1 \mathrm{ml}$ of pyridine were added to the mixture and magnetically stirred at room temperature under $\mathrm{N}_{2}$ for $1 \mathrm{~h}$. $1 \mu \mathrm{l}$ of this reaction mixture was analyzed by GC/MS. The silylated samples were injected into a GC-MS system consisted of an HP5972A mass spectrometer linked to a HP5890A series II gas chromatograph (Agilent Technologies, Palo Alto, CA, USA) equipped with a $30 \mathrm{~m} \times 0.25 \mathrm{~mm}$ i.d. HP-5MS (5\% phenylpolydimethylsiloxane) capillary column.
A

K562

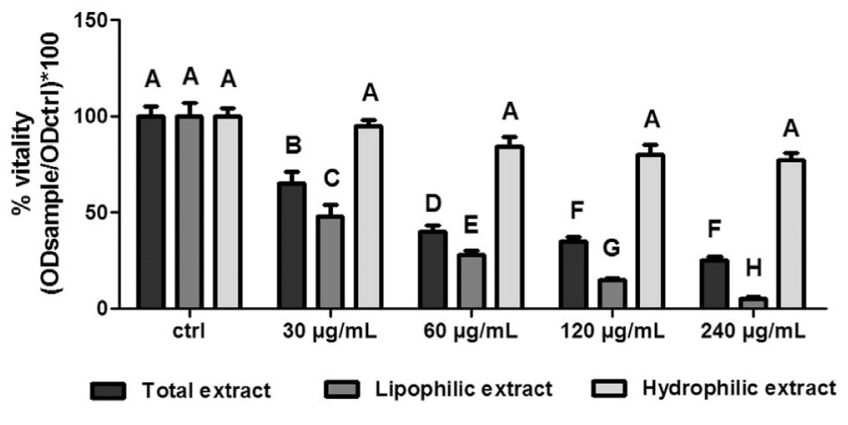

B

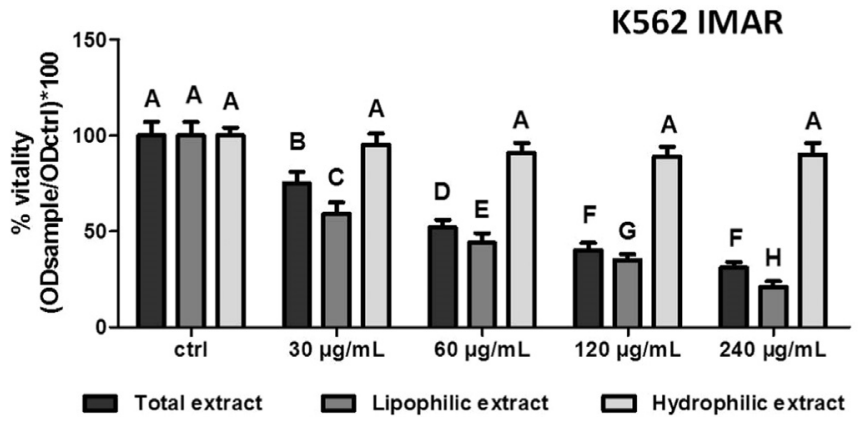

Fig. 1. MTT assay of K562 and K562 IMAR cells treated with different concentrations of CCL extraction fractions for 24 h. A: K562 cell line. B: K562-IMAR cell line. Values with the same letter are not significantly different, while values with different letter are significantly different $(\mathbf{p}<\mathbf{0 . 0 0 1}$, one-way ANOVA followed by Dunnet's Multiple Comparison Test, as post-hoc Each sample was run in triplicate $(n=4)$.
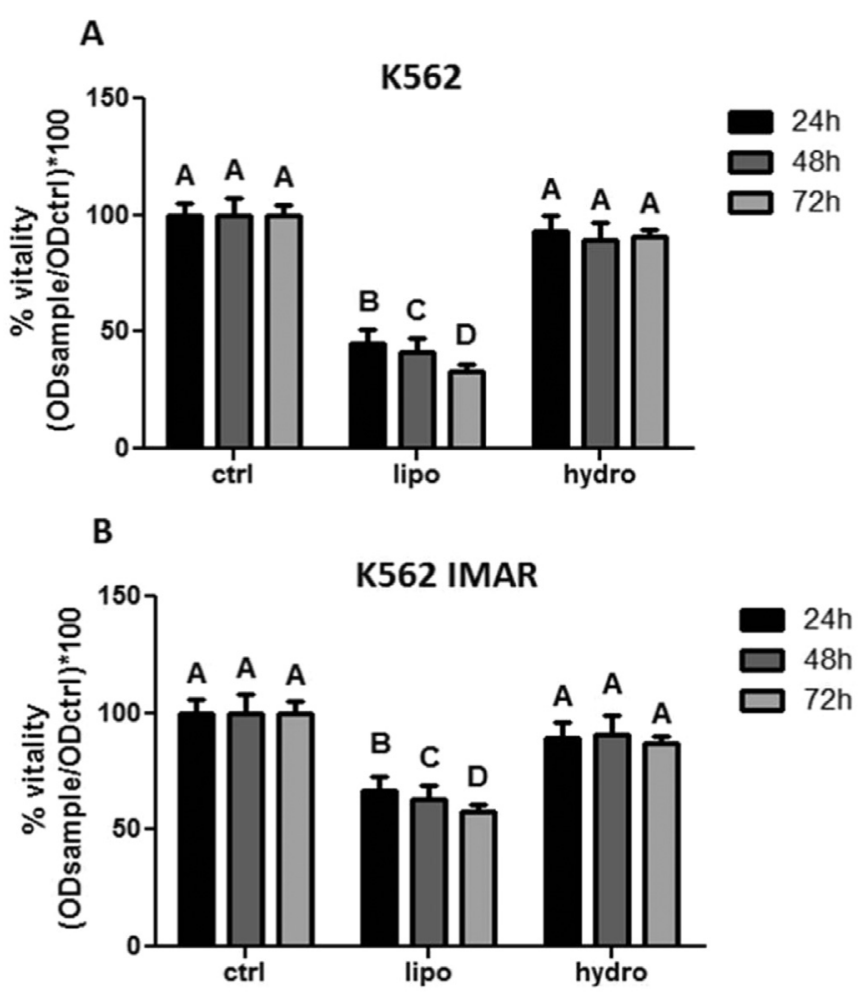

Fig. 2. Time course and MTT assay of K562 and K562 IMAR cells treated with $60 \mu \mathrm{g} / \mathrm{ml}$ of CCL lipophilic or hydrophilic fractions. A: K562 cell line. B: K562-IMAR cell line. *p < 0.05 and ${ }^{* *} \mathrm{p}<0.001$ one-way ANOVA followed by Dunnet's Multiple Comparison Test, as post-hoc. Each sample was run in triplicate $(n=4)$. 
A

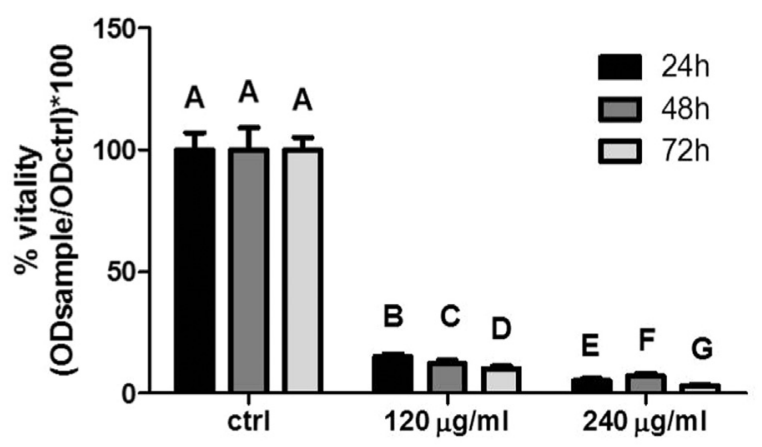

B

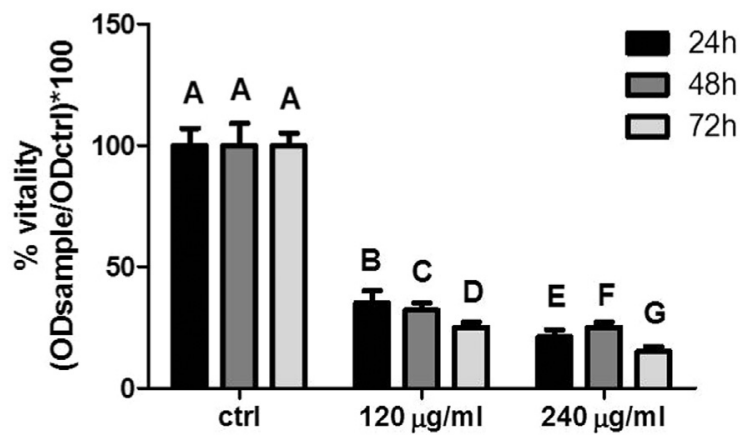

Fig. 3. Time course and MTT assay of K562 and K562 IMAR cells treated with different concentrations of CCL lipophilic fraction. A: K562 cell line. B: K562-IMAR cell line. Values with the same letter are not significantly different, while values with different letter are significantly different $(\mathrm{p}<0.001$, one-way ANOVA followed by Dunnet's Multiple Comparison Test, as post-hoc Each sample was run in triplicate.

Helium, at a flow rate of $1 \mathrm{ml} / \mathrm{min}$ was used as carrier gas. GC was performed in the splitless mode with 1 min splitless-time. The column oven temperature was maintained at $40{ }^{\circ} \mathrm{C}$ for 4 min then programmed at $16^{\circ} \mathrm{C}$ min to $280^{\circ} \mathrm{C}$, which was held for $5 \mathrm{~min}$. A post run of $10 \mathrm{~min}$ at $70^{\circ} \mathrm{C}$ was sufficient for the next injection. The injection port and detector temperatures were 250 and $280{ }^{\circ} \mathrm{C}$, respectively. The mass spectrometer was operated at 1000 resolution in electron-impact positive ionization mode (EI+), electron energy $70 \mathrm{eV}$; scanning was from 35 to 450 uma at a scan speed of $1 \mathrm{~s}$ decade- 1 and with $0.2 \mathrm{~s}$ inter-scan time. The source temperature was $200{ }^{\circ} \mathrm{C}$.

\subsection{HPLC analysis of Le extracts}

The HPLC apparatus, was a Hewlett-Packard 2100 system equipped with a Rheodyne injector and fitted with a $20 \mathrm{ll}$ loop and a $\mathrm{UV}$ detector set at $254 \mathrm{~nm}$. A Phenomenex Jupter $\mathrm{C}_{18}, 250-4.6 \mathrm{~mm}$, $5 \mu \mathrm{m}$ column was used for the analysis, heated at $30{ }^{\circ} \mathrm{C}$ with an elution gradient from $100 \%$ of A 5 min to $35 \%$ of $\mathrm{B}$ over $10 \mathrm{~min}$, followed by $35-90 \%$ of $\mathrm{B}$ in $5 \mathrm{~min}$, A being $\mathrm{H}_{2} \mathrm{O}$ and $\mathrm{B} \mathrm{CH}_{3} \mathrm{CN}$. Flow rate was $1 \mathrm{ml} /$ min. Six peaks were detected in the chromatogram. The sample was purified by semipreparative RP-HPLC chromatography Phenomenex Jupter $\mathrm{C}_{18}, 250 \times 10 \mathrm{~mm}, 10 \mu \mathrm{m}$, UV $272 \mathrm{~nm}, 4.0 \mathrm{ml} / \mathrm{min}$ with the same elution gradient. (see Supporting information).

\subsection{NMR analysis}

${ }^{1} \mathrm{H}$ NMR spectra were recorded at $300 \mathrm{MHz}$, while ${ }^{13} \mathrm{C}$ NMR spectra were measured at $75 \mathrm{MHz}$ on a Bruker Avance 300 spectrometer (Bruker, Fällanden, Switzerland). Spectral analysis was performed at $293 \mathrm{~K}$ on diluted solutions of each compound by using DMSO as the solvent. Chemical shifts $(\delta)$ are reported in ppm and referenced to
DMSO (2.50 ppm for ${ }^{1} \mathrm{H}$ and $39.51 \mathrm{ppm}$ for ${ }^{13} \mathrm{C}$ spectra). Coupling constants $(\mathrm{J})$ are reported in Hertz $(\mathrm{Hz})$.

\subsection{LC-QTOF-MS analysis}

Liquid chromatography-mass spectrometry (LC-MS) analyses were carried out using an Agilent 6540 UHD Accurate - Mass QTOF LC-MS (Agilent, Santa Clara, CA) fitted with an electrospray.

ionization source (Dual AJS ESI) operating in positive ion mode. Chromatographic separation was achieved using a $\mathrm{C}_{18} \mathrm{RP}$ analytical column (Poroshell 120, SB-C $18,50 \times 2.1 \mathrm{~mm}, 2.7 \mu \mathrm{m}$ ) at $40{ }^{\circ} \mathrm{C}$.

with an elution gradient from $20 \%$ to $35 \%$ of $\mathrm{B}$ over $30 \mathrm{~min}$, followed by $35-90 \%$ of $\mathrm{B}$ in $5 \mathrm{~min}$, A being $\mathrm{H}_{2} \mathrm{O}(0.1 \% \mathrm{FA})$ and $\mathrm{B}$ $\mathrm{CH}_{3} \mathrm{CN}$. Flow rate was $0.4 \mathrm{ml} / \mathrm{min}$.

\subsection{Cell culture}

The leukemic K562 cell line was obtained by Biological Bank and Cell Factory-IST Genova. Cells were maintained in phase expansion and were grown in RPMI 1640 with L-glutamine supplemented with $10 \%$ (v/v) heat-inactivated FBS, $1 \%$ penicillin/streptomycin in humidified atmosphere of $5 \% \mathrm{CO}_{2}$ at $37^{\circ} \mathrm{C}$. The $\mathrm{K} 562$ cell line was made resistant to imatinib (IM) by exposing the cells to this drug at $1 \mu \mathrm{M}$ concentration for consecutive 45 days. During treatment with IM, the medium was changed every 3 days and the cultures were subjected to purification cycles by layering on Ficoll, in order to remove the dead cells IM sensitive. The resistant cells were then plated in a new flask and grown as described for the non-resistant cell variant (Klein et al., 1976). In all experiments growing cells at optimal concentration $\left(1 \times 10^{5}\right.$ a $5 \times 10^{5}$ cells $/ \mathrm{ml}$ ) were placed in 24 or 96 well plate and then treated with vehicle or various concentration of total, lipophilic or hydrophilic extracts. After different time points, the treatment cultures were tested for proliferative activity and p210 or c-Abl protein expression by western blotting analysis.

\subsection{MTT assay}

Cell viability was determined by the MTT assay, measuring the reduction of 3-(4,5-dimethylthiasol-2-yl)-2,4,-diphenyltetrazolium bromide (MTT) by mitochondrial succinate dehydrogenase, as previously described (Perri et al., 2016). The MTT enters the cells and passes into the mitochondria where is reduced to an insoluble, coloured, formazan product. The amount of colour produced is directly proportional to the number of viable cells. Leukemic cells were incubated with different amounts of total, lipophilic and hydrophilic extracts (30-60-120-240 $\mu \mathrm{g}$ ) at different time points in 96-wellplates. After lipophilic extract sub-fractioning, cells were treated with the most abundant compounds, at different concentrations (3-7.5$15-30-60 \mu \mathrm{M})$ for $24 \mathrm{~h}$. At time of assay, $10 \mu \mathrm{l}$ of MTT $(5 \mathrm{mg} / \mathrm{ml}$ in PBS) was added to each well and incubated for $3 \mathrm{~h}$ at $37^{\circ} \mathrm{C}$. The medium was then carefully aspirated, and $100 \mu$ l of dimethylsulfoxide (DMSO) was added to solubilize the coloured formazan product, agitating the plates for $5 \mathrm{~min}$ on a shaker. The absorbance of each well was measured with a microtiter plate reader (Synergy H1 MultiMode Reader-Hybrid Technology ${ }^{\mathrm{TM}}$ ) at a test wavelength of $570 \mathrm{~nm}$ with a reference wavelength of $690 \mathrm{~nm}$. The optical density (OD) was calculated as the difference between the absorbance at the reference wavelength and the absorbance at the test wavelength. Percent viability was calculated as (OD of drug treated sample/OD of control) $1 * 100$.

\subsection{Western blot analysis}

Cultured cells were lysed with $200 \mu \mathrm{l}$ ice-cold PBS containing $1 \%$ Triton X-100, 0.5\% sodium deoxycholate, $0.1 \%$ SDS and protease inhibitors (1 mM phenylmethylsulfonylfluoride, $10 \mathrm{mg} / \mathrm{ml}$ aprotinin and $10 \mathrm{mg} / \mathrm{ml}$ leupeptin), as previously described (Cione et al., 2009). 
A

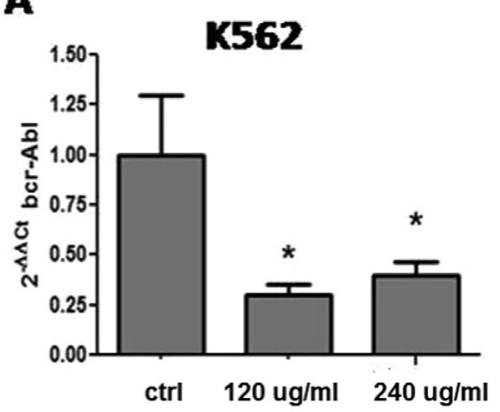

B
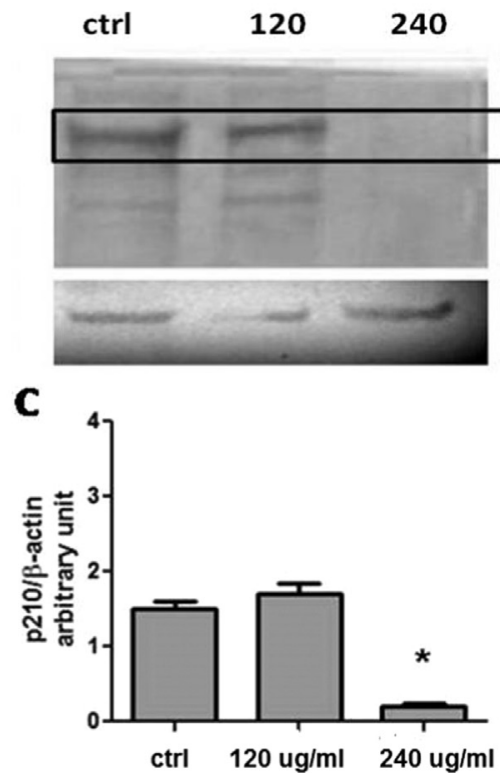

D

\section{K562 IMAR}

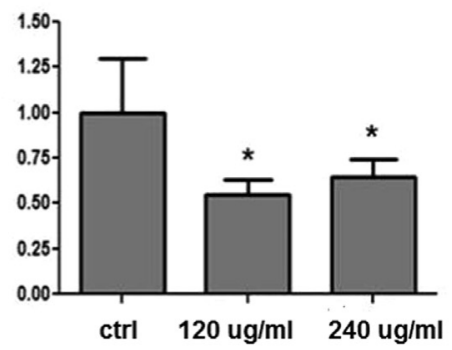

$\mathbf{E}$

ctrl $\quad 120 \quad 240 \mathrm{ug} / \mathrm{ml}$
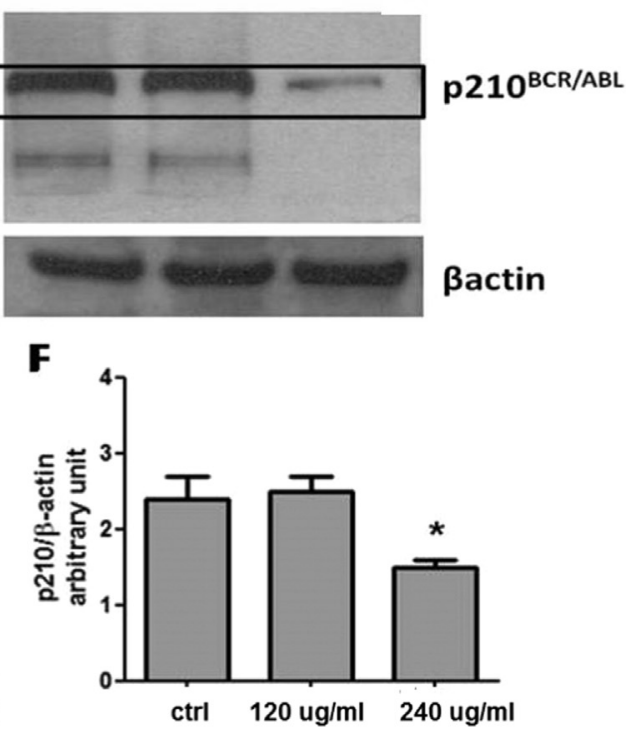

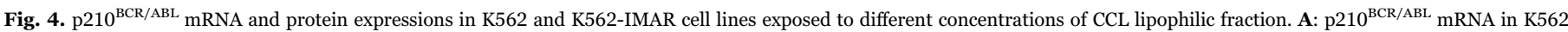

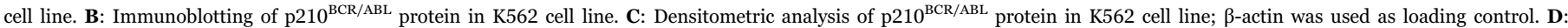

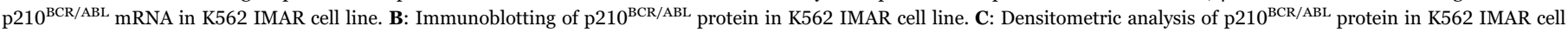
line; $\beta$-actin was used as loading control. ${ }^{*} \mathrm{p}<0.05$ and ${ }^{* *} \mathrm{p}<0.001$ one-way ANOVA followed by Dunnet's Multiple Comparison Test, as post hoc), ( $\mathrm{n}=3$ ).

Lysates were centrifuged $\left(13,000 \mathrm{~g}\right.$ at $4{ }^{\circ} \mathrm{C}$ for $\left.30 \mathrm{~min}\right)$ and the supernatant protein content was quantified. Proteins $(50 \mu \mathrm{g})$ were resolved by $15 \%$ SDSPAGE, and transferred to a nitrocellulose membrane (Hybond-C; Amersham Biosciences, Piscataway, NJ). The membrane was blocked with $5 \%$ bovine serum albumin and probed with the specific primary antibody c-Abl (Invitrogen). After washing, membranes were incubated with HRP-conjugated secondary antibody. Peroxidase activity was visualized with the Amersham Pharmacia Biotech ECL system according to the manufacturer's instructions. The protein content was determined densitometrically. The loading control was detected by immunoblot of $\beta$-actin protein.

\subsection{Quantitative real time PCR ( $q R T-P C R)$}

Quantitative Real-Time RT-PCR was used for determining expression levels of $\mathrm{p} 210^{\mathrm{BCR} / \mathrm{ABL}}$ oncoprotein kinase in both cell lines tested. Briefly, total RNA was isolated and purified by spin protocol using the PureLink $^{\mathrm{TM}}$ RNA Mini kit (12183018A Invitrogen) according to the manufacturer's instructions. Two micrograms of total RNA were reverse-transcribed using components of a High Capacity cDNA Reverse Transcription Kit (Applied Biosystems). Following reverse transcription, quantitative PCR amplification was performed on an StepOnePlus ${ }^{\mathrm{TM}}$ System (Applied Biosystems) using TaqMan Universal PCR Master Mix (Applied Biosystems), and gene-specific TaqMan PCR primers for $\mathrm{p} 210^{\mathrm{BCR} / \mathrm{ABL}}$ and $\beta$-actin (Applied Biosystems). Relative gene expression levels were normalized to the basal, untreated sample chosen as calibrator. Results are expressed as folds of difference in gene expression relative to $\beta$-actin mRNA and calibrator, calculated following the $\Delta$ Ct method, as follows:

Relativeexpression (folds) $=2^{-(\Delta \text { Ctsample }-\Delta \text { Ctcalibrator })}$

where $\Delta \mathrm{Ct}$ values of the sample and calibrator were determined by subtracting the average $\mathrm{Ct}$ value of the $\beta$-actin mRNA reference gene from the average $\mathrm{Ct}$ value of the analyzed gene.

\subsection{Statistical analysis}

Statistical analysis was performed using GraphPad Prism 5.0 software. Statistical differences were determined by One-way analysis of variance (ANOVA) followed by Dunnet's Multiple Comparison Test, and the results were expressed as mean $\pm \mathrm{SD}$ from $\mathrm{n}$ independent experiments. Differences were considered statistically significant for ${ }^{*} \mathrm{p}$ $<0.05$ and ${ }^{* *} \mathrm{p}<0.001$.

\section{Results}

3.1. Total CCL extract and lypophilic fraction of CCL inhibited growth of K562 and K562 imatinib-resistant (IMAR)

To investigate the effect of CCL on growth of K562 and K562 IMAR, 


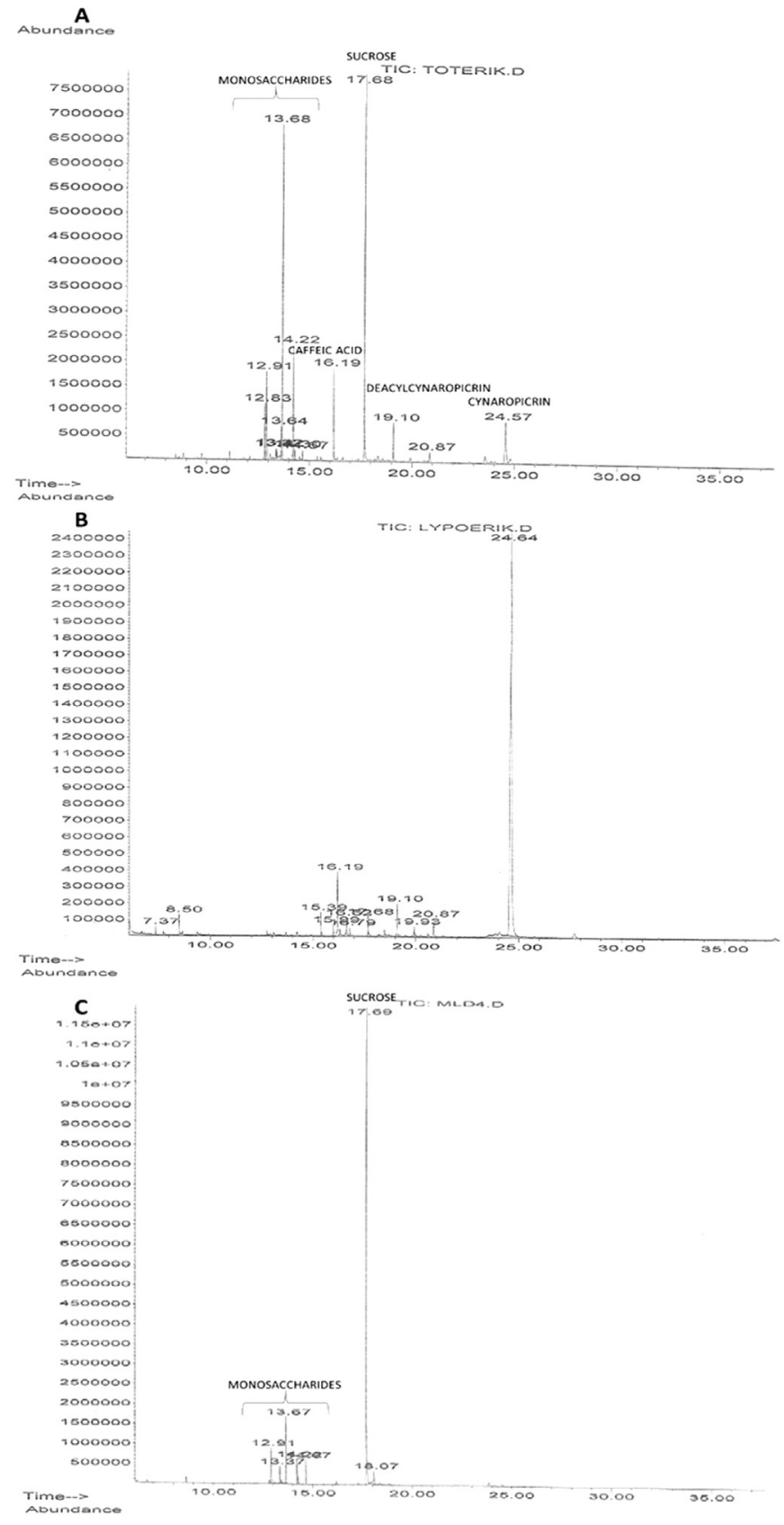

Fig. 5. GC-MS chromatogram of the TMS-derivatized extracts. A: total extract (Te); B: lipophilic extract (Le) and $\mathbf{C}$ : hydrophilic extract (He)

cells were incubated for $24 \mathrm{~h}$ with increasing concentration of phytochemical fractions from total (by methanol maceration) lipophilic (by hexane extraction) or hydrophilic extracts (by water extraction) of CCL. Cell viability of both cell types measured by MTT assay was inhibited in a dose-dependent fashion by the exposure of cell cultures to total and lipophilic extract, suggesting similar sensitivities of in K562 and K562 IMAR cell lines cell to these phytochemical fractions. No difference of cellular proliferation was detected in both cell lines when treated with hydrophilic extract (Fig. 1, panels A and B).

\subsection{CCL lipophilic fraction inhibited growth of K562 and K562 IMAR in a time-independent manner}

To further validate the inhibitory effect of lipophilic CCL fraction on cellular proliferation we exposed K562 and K562 IMAR to a fixed concentration of the extract and cell viability was assessed by MTT assay at 24, 48 and $72 \mathrm{~h}$. As illustrated in Fig. 2, panels A and B the exposure of both cell lines to the lipophilic CCL fraction at concentration of $60 \mu \mathrm{g} / \mathrm{ml}$ was able to inhibit in a time-independent manner cell viability, highlighting a reduction of vitality of about $46-48 \%$ at both 24, 48 and $72 \mathrm{~h}$. Similar behaviour was also observed when both cell cultures were exposed to 120 and $240 \mu \mathrm{g} / \mathrm{ml}$ concentrations for 24,48 and $72 \mathrm{~h}$ (Fig. 3, panels A and B). Any affects was shown by components into the hydrophilic fraction at the same fixed concentration and at all the times tested (Fig. 2, panels $\mathbf{A}$ and $\mathbf{B}$ ).

\subsection{CCL lipophilic fraction impaired $p 210^{B C R / A B L} \mathrm{mRNA}$ and protein expressions in K562 and K562 IMAR cell lines}

To address the mechanism of CCL lipophilic fraction-mediated growth inhibition in CML cells we analyzed the expression of $\mathrm{p} 210^{\mathrm{BCR} /}$ ${ }_{\mathrm{ABL}}$ oncoprotein kinase in K562 and K562 IMAR cell lines treated with different concentrations of lipophilic CCL extract at both mRNA and protein levels. Twenty-four hours exposure of K562 and K562 IMAR to $120 \mu \mathrm{g} / \mathrm{ml}$ or $240 \mu \mathrm{g} / \mathrm{ml}$ of CCL lipophilic fraction dramatically decreased $\mathrm{p} 210^{\mathrm{BCR} / \mathrm{ABL}}$ mRNA levels (Fig. 4, panels A and D). Immunoblotting technique revealed a dose-dependent decrease of p210 $\mathrm{BCR} / \mathrm{ABL}$ protein in both cell lines (Fig. 4, panels B and E), with a marked effect in K562 cells compared to K562 IMAR as shown by densitometric analysis (Fig. 4, panels $\mathbf{C}$ and F).

\subsection{Chemical characterization of the CCL extracts (Te, Le, He)}

At first the three extracts were analyzed by GC-MS after a proper silylation of the samples. The chromatograms of the three derivatized samples are shown in Fig. 5, panels A, B and C. Comparing the GCMS chromatogram of total extract (Fig. 5, panel A) with the chromatograms of both lipophilic and hydrophilic extract it was observed that in the Le chromatogram, the peak at $\mathrm{RT}=24.64 \mathrm{~min}$ represented the main component of the extract (accounting for $76.33 \%$ of the peak area of the total ion-current chromatogram) (Fig. 5, panel B). The same peak was evident in the $\mathrm{Te}$ extract at $\mathrm{RT}=24.67 \mathrm{~min}$ accounting for $33 \%$ while it was totally absent in the He chromatogram (Fig. 5, panel C). As the biological test demonstrated that only the Le extract showed significant cytotoxicity we decided to isolate the main component in the Le extract by semipreparative RP-HPLC chromatography (see Supplemental material). The structural characterization of this compound was performed by ${ }^{1} \mathrm{H}-{ }^{13} \mathrm{C}$ NMR and LC/MS analysis. The spectroscopic data were closely comparable to published data for cynaropicrin (Ramos et al., 2013) (See Supplemental material).

3.5. Cynaropicrin and its deacyl derivative affected cell viability of K562 and K562 IMAR cell lines

Chemical characterization allowed us to identify cynaropicrin and deacyl cynaropicrin as components of lipophilic fraction of CCL. To investigate the effect of these two molecules on cell viability, K562 and K562 IMAR cultures were exposed to increasing concentration (from 3 up to $60 \mu \mathrm{M}$ ) of cynaropicrin or of its deacyl derivative for $24 \mathrm{~h}$ and then analyzed through MTT assay. As depicted in Fig. 6 and Fig. 7, treatment of both cell lines with cynaropicrin and deacyl cynaropicrin induced a dramatic decrease of cell viability with a typical doseresponse curve. $\mathrm{IC}_{50}$ determination of cynaropicrin revealed a value of 11.4 in K562 and 13.2 in K562 IMAR cells (Fig. 6, panels A and B), while its deacyl derivative showed an $\mathrm{IC}_{50}$ value of $12.6 \mu \mathrm{M}$ and $9.6 \mu \mathrm{M}$ in both cell cultures, respectively (Fig. 7, panels $\mathbf{A}$ and B).

3.6. Cynaropicrin and deacyl cynaropicrin regulated $p 210^{B C R / A B L}$ protein expression in K562 and K562 IMAR cell lines

To better characterized the cytotoxic effect of the two compounds, K562 and K562 IMAR cell lines were treated with cynaropicrin or 
A

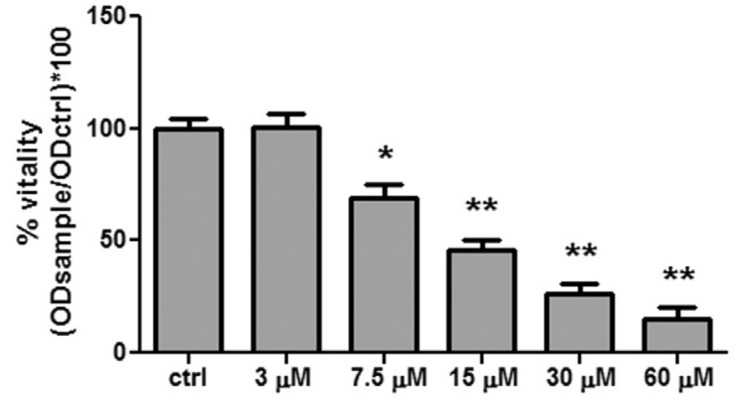

C

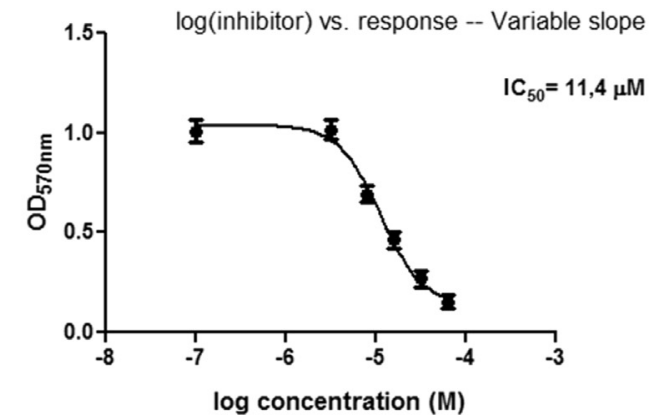

B

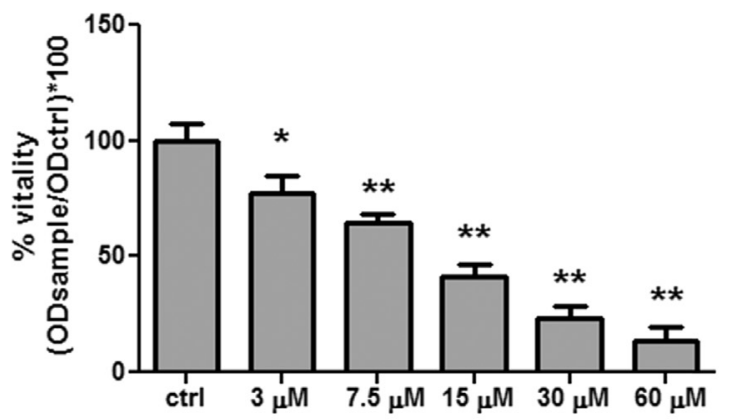

D

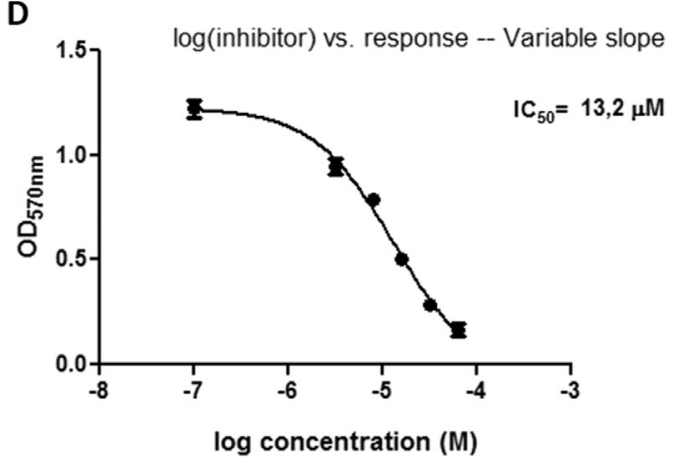

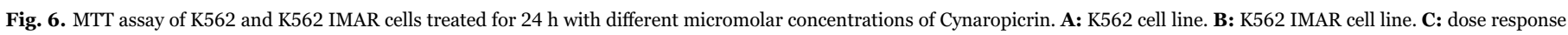

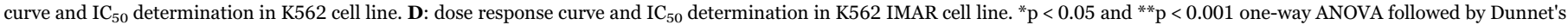
Multiple Comparison Test, as post hoc. Each sample was run in triplicate $(n=4)$.

A

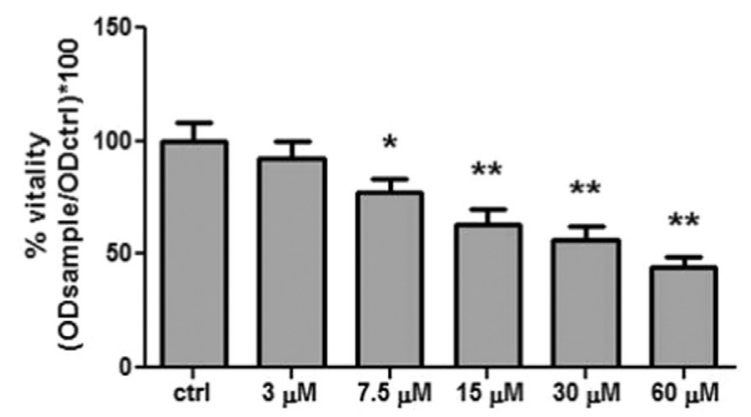

C

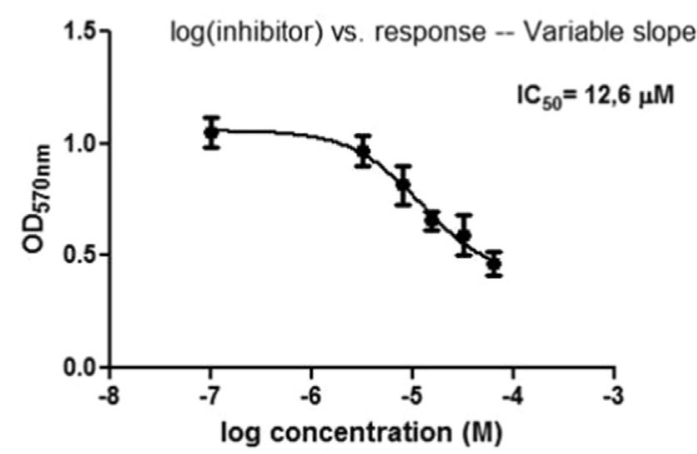

B

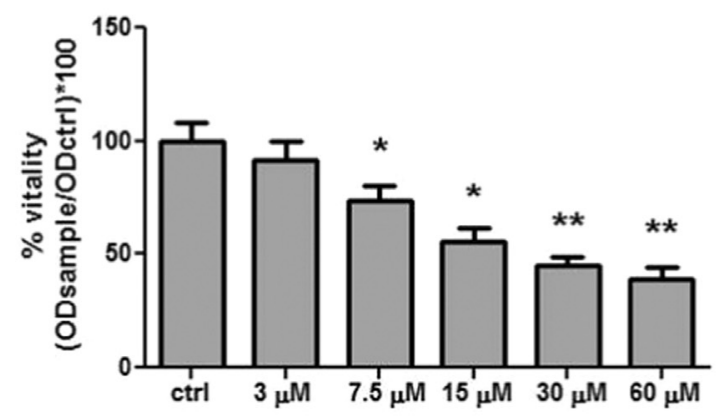

D

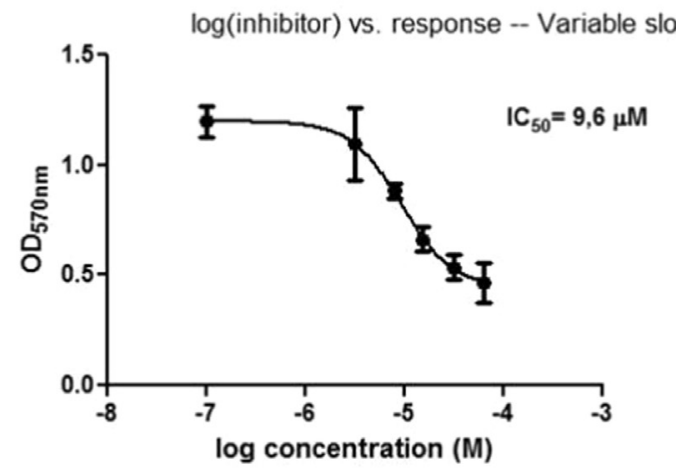

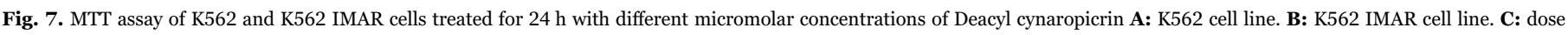

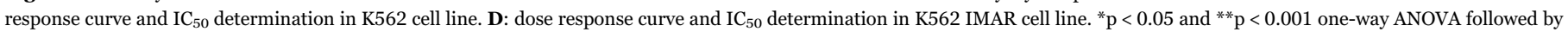
Dunnet's Multiple Comparison Test, as post hoc. Each sample was run in triplicate $(n=4)$. 
A

A

B

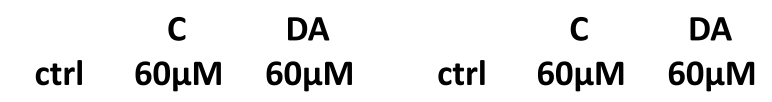
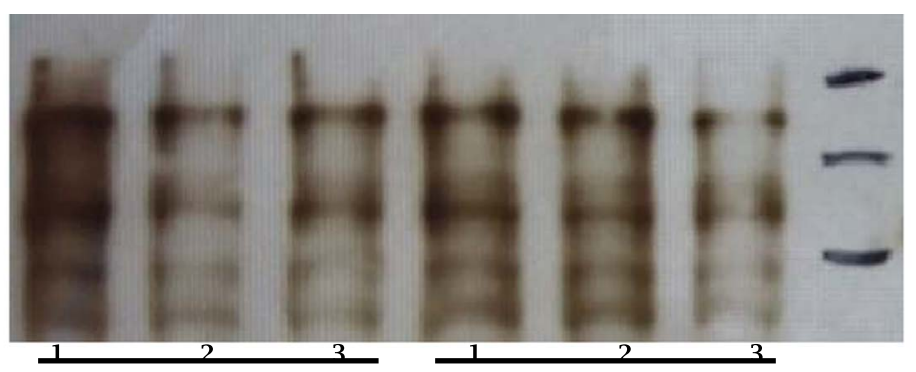

$250 \mathrm{Kd}$ $150 \mathrm{Kd}$

$89 \mathrm{Kd}$

K562

K562 IMAR

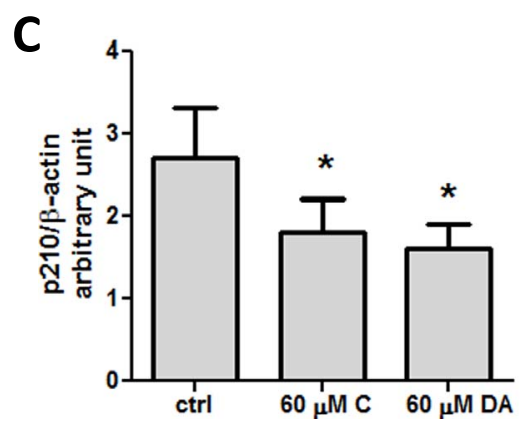

D

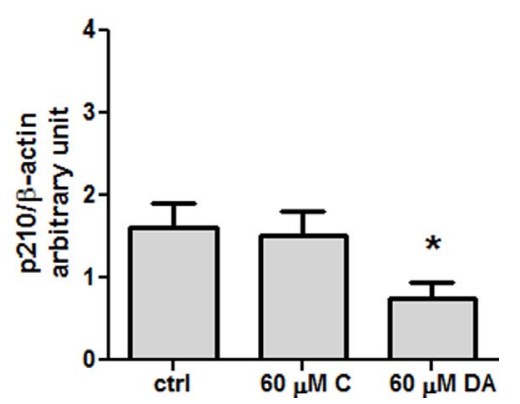

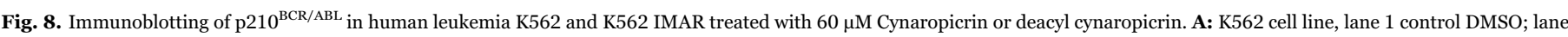

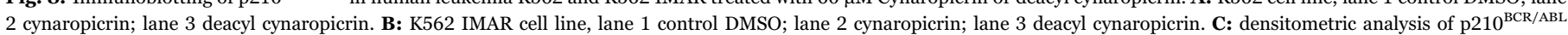

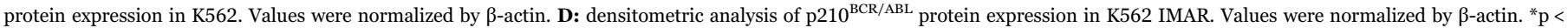
0.05 and ${ }^{* *} \mathrm{p}<0.001$ one-way ANOVA followed by Dunnet's Multiple Comparison Test, as post-hoc $(\mathrm{n}=3)$.

deacyl cynaropicrin at concentrations of $60 \mu \mathrm{M}$ for $24 \mathrm{~h}$ and then p210 $10^{\mathrm{BCR} / \mathrm{ABL}}$ oncoprotein expression was analyzed by Western Blotting technique. As shown in Fig. 8, panels A and B, cynaropicrin and its deacyl derivative decreased $\mathrm{p} 210^{\mathrm{BCR} / \mathrm{ABL}}$ protein levels in both cell lines, however a marked effect was highlighted in K562 IMAR cell line, as revealed by densitometric analysis (Fig. 8, panels $\mathbf{C}$ and $\mathbf{D}$ ).

\section{Discussion}

CML is a progressive and often fatal myeloproliferative disorder accounting for about $20 \%$ of newly diagnosed cases of leukemia in adults. The ABL kinase inhibitor imatinib greatly improved the outcome in CML patients (Druker et al., 2001), however some evidence suggests that it cannot eradicate the disease (Holtz et al., 2007), thus several strategies in association with TKI, are currently being studied. In this view, natural products have afforded a rich source of compounds that have found many applications in the fields of medicine, pharmacy and biology and in recent years they have drawn a great deal of attention because of its potential effects to suppress cancer or to reduce the risk of cancer development. Early studies performed on in vitro models of leukocyte lineage cancer cell (Cho et al., 2004) demonstrated that methanol extract of CCL flower and/or cynaropicrin had a remarkable anti-proliferative activity. Herein, using the classical in vitro approach for studying the molecular mechanisms in CML and for screening new drugs, we highlighted for the first time how total and lipophilic extracts of CCL displayed a potent dose-dependent and time independent inhibition of cell proliferation (Figs. 1 and 2) in both K562 and K562 IMAR cell lines. Qt-PCR and Western blot techniques revealed that the cell growth inhibition was associated to a dramatic decrease of $\mathrm{p} 210^{\mathrm{BCR} / \mathrm{ABL}}$ oncoprotein kinase expression suggesting that the antiproliferative effect of CCL lipophilic fraction is likely due to the inhibition at transcriptional level of Bcr-Abl fusion gene in both cell lines (Fig. 4). However this effect is evident at $240 \mu \mathrm{g} / \mathrm{ml}$, while the concentration of $120 \mu \mathrm{g} / \mathrm{ml}$ was able to affect only the Bcr-Abl mRNA levels. This discrepancy could be explained considering that protein expression is not necessarily proportional to mRNA levels. Indeed, if transcription is down regulated, the pool of already synthesized mRNA might be efficiently translated. As a result, protein product accumulation level might remain stable. In addition, the protein might be a long lived protein which get accumulated over time while the mRNA turnover is quick or the protein stability might be increased due to post-translational modifications. At last, the inhibition of protein level induced by drug exposure could be dose-dependent. Most importantly, lipophilic fraction analyzed by GC/MS highlighted the presence caffeic acid (4\%), long chain fatty acids (3\%), traces of sucrose $(2 \%)$ and sesquiterpene lactones (86\%) and purification of those components by HPLC permitted us to recover sesquiterpene lactones family. The chemical characterization by NMR and Q-TOF/MS methods allowed us to identify cynaropicrin as the main sesquiterpene lactone while its deacyl derivative represented only the $2 \%$ of the total lipophilic extract (Fig. 5). Both molecules exerted a sharp cytotoxic activity in K562 and K562 IMAR cell cultures in a dose-dependent fashion (Fig. 6) also indicating that the acyl group in the molecule is not fundamental for their biological activity (Fig. 1 in Supporting information). Moreover, cynaropicrin and deacyl cynaropicrin $\mathrm{IC}_{50}$ value is comparable which suggested a similar sensitivity of K562 and K562 IMAR cell lines to both molecules. Of interest the evidence that cynaropicrin and deacyl cynaropicrin at micromolar concentrations potently down regulated p210 ${ }^{\mathrm{ABL} / \mathrm{BCL}}$ protein expression in our experimental model. However it is important to note that in K562 cell line where imatinib resistance was induced (Fig. 8), p210 protein expression didn't change by $60 \mu \mathrm{M}$ Cynaropicrin treatment, while it decreased to a low level by the same dose of Deacyl cynaropicrin. In cancer cells the occurrence of new mutations profoundly affects their drug or compounds sensitivity as 
frequently observed in the clinical practice and in vitro models that mimic this condition. In K562IMAR the presence of novel mutations at the level of bcr-abl gene confers new phenotypic features thus rendering this cell line unresponsive not only to imatinib but also to other unrelated compounds. It has been reported that specific amino acid mutations in the Bcr-Abl kinase domain lead to the expression of the mutant protein T315I Abl which in turn is responsible for the most of acquired resistance to imatinib (Kantarjian et al., 2006). Although the change to second-generation of TKIs such as dasatinib and nilitinib can overcome imatinib resistance in most of the mutated patients, these drugs are often ineffective in the presence of the T315I mutation (Shah et al., 2004; Martinelli et al., 2005; O'Hare et al., 2005; Li, 2007; Gaboriaud-Kolar et al., 2016) and disease relapsing as well as drug resistance also occurs when they are used alone as second line options (Jabbour and Kantarjian, 2014). Therefore, an effective strategy may be minimizing the activity of Bcr-Abl by inhibiting the expression of Bcr-Abl at the protein or mRNA level as suggested by early (Nimmanapalli et al., 2003; Chen et al., 2006). In this conceptual framework the down regulation of $\mathrm{p} 210^{\mathrm{BCR} / \mathrm{ABL}}$ oncoprotein kinase induced by cynaropicrin or its deacyl derivative presented here, suggests that these molecules could represent an important, novel and promising strategy for both potentiate the ability of imatinib and/ or its analogues to induce cancer growth arrest in CML and to retard or overcome the resistance of CML to chemotherapy. In this view, it is worth to note that cynaropicrin and its derivative are composed of complex structures therefore traditional systematic structure function studies could lead to an optimization of their properties as is already demonstrate for vinblastine and vincristine (Vinca alkaloids) often considered prototypical members of natural products whence semisynthetic modification yielded at two classes of analogues that enhance their potency by 10-fold (Allemann et al., 2016).

\section{Author's contributions}

Dr(s) Russo, Perri and Caroleo, have full access to all of the data in the study and take responsibility for the integrity of the data and the accuracy of the data analysis.

Study concept and design: Russo, Di Gioia, and Cione.

Acquisition of data: Russo, Perri, Di Gioia, and Nardi.

Analysis and interpretation of data: Perri, Cione, Caroleo and Nardi.

Drafting of the manuscript: Di Gioia and Cione.

\section{Statement of interest}

The authors have declared that no competing interests exist.

\section{Acknowledgements}

The author thanks the former of this project Valentino Carito and Attilio Pingitore which take care about K562 IMAR cell line.

\section{Appendix A. Supplementary material}

Supplementary data associated with this article can be found in the online version at doi:10.1016/j.jep.2017.03.026.

\section{References}

Allemann, O., Brutsch, M., Lukesh, J.C., Brody, D.M., Boger, D.L., 2016. Synthesis of a potent vinblastine: rationally designed added benign complexity. J. Am. Chem. Soc. 138, 8376-8379.

Ben-Neriah, Y., Daley, G.Q., Mes-Masson, A.M., Witte, O.N., Baltimore, D., 1986. The chronic myelogenous leukemia-specific p210 protein is the product of the bcr/abl hybrid gene. Science 233, 212-216.

Cayssials, E., Guilhot, F., 2016. Beyond tyrosine kinase inhibitors: combinations and other agents. Best Pract. Res. Clin. Haematol. 29 (3), 271-283.

Chen, R., Gandhi, V., Plunkett, W., 2006. A sequential blockade strategy for the design of combination therapies to overcome oncogene addiction in chronic myelogenous leukemia. Cancer Res. 66 (22), 10959-10966.

Cho, J.Y., Kim, A.R., Jung, J.H., Chun, T., Rhee, M.H., Yoo, E.S., 2004. Cytotoxic and pro-apoptotic activities of cynaropicrin, a sesquiterpene lactone, on the viability of leukocyte cancer cell lines. Eur. J. Pharm. 492 (2-3), 85-94.

Cione, E., Pingitore, A., Perri, M., Genchi, G., 2009. Influence of all-trans-retinoic acid on oxoglutarate carrier via retinoylation reaction. Biochem. Biophys. Acta 1791 (1), $3-7$.

Daley, G.Q., Baltimore, D., 1988. Transformation of an interleukin 3-dependent hematopoietic cell line by the chronic myelogenous leukemia-specific p210 bcr/abl protein. Proceedings Natl. Acad. Sci. USA. 5, 9312-9316.

Daley, G.Q., van Etten, R.A., Baltimore, D., 1990. Induction of chronic myelogenous leukemia in mice by the $210^{\text {bcr/abl }}$ gene of the Philadelphia chromosome. Science $247,824-830$.

Druker, B.J., Talpaz, M., Resta, D.J., Peng, B., Buchdunger, E., Ford, J.M., Lydon, N.B., Kantarjian, H., Capdeville, R., Ohno-Jones, S., Sawyers, C.L., 2001. Efficacy and safety of a specific inhibitor of the BCR-ABL tyrosine kinase in chronic myeloid leukemia. N. Engl. J. Med. 344 (14), 1031-1037.

Gaboriaud-Kolar, N., Myrianthopoulos, V., Vougogiannopoulou, K., Gerolymatos, P., Horne, D.A., Jove, R., Mikros, E., Nam, S., Skaltsounis, A.L., 2016. Natural-based indirubins display potent cytotoxicity toward wild-type and T315I-resistant leukemia cell lines. J. Nat. Prod.. http://dx.doi.org/10.1021/acs.jnatprod.6b00285, Oct. 11. [Epub Print.].

González-Vallinas, M., González-Castejón, M., Rodríguez-Casado, A., Ramírez de Molina, A., 2013. Dietary phytochemicals in cancer prevention and therapy: a complementary approach with promising perspectives. Nutr. Rev. 71 (9), 585-599.

Holtz, M., Forman, S.J., Bhatia, R., 2007. Growth factor stimulation reduces residual quiescent chronic myelogenous leukemia progenitors remaining after imatinib treatment. Cancer Res. 67 (3), 1113-1120.

Jabbour, E., Kantarjian, H., 2014. Chronic myeloid leukemia: 2014 update on diagnosis, monitoring, and management. Am. J. Hematol. 89 (5), 547-556.

Kantarjian, H.M., Talpaz, M., Giles, F., O’Brien, S., Cortes, J., 2006. New insights into the pathophysiology of chronic myeloid leukemia and imatinib resistance. Ann. Intern. Med. 145, 913-923.

Klein, E., Ben-Bassat, H., Neumann, H., Ralph, P., Zeuthen, J., Polliack, A., Vánky, F., 1976. Properties of the K562 cell line, derived from a patient with chronic myeloid leukemia. Int. J. Cancer 18 (4), 421-431.

Lahlou, M., 2013. The success of natural products in drug discovery. Pharmacol. Pharm. 4, 17-31.

Li, S., 2007. Src kinase signaling in leukaemia. Int. J. Biochem. Cell Biol. 39, 1483-1488.

Martinelli, G., Soverini, S., Rosti, G., Baccarani, M., 2005. Dual tyrosine kinase inhibitors in chronic myeloid leukemia. Leukemia 19, 1872-1879.

McLaughlin, J., Chianese, E., Witte, O.N., 1987. In vitro transformation of immature hematopoietic cells by the p210 BCR/ABL oncogene product of the Philadelphia chromosome. Proceedings Natl. Acad. Sci. USA, 84, 6558-6562.

Moen, M.D., McKeage, K., Plosker, G.L., Siddiqui, M.A., 2007. Imatinib: a review of its use in chronic myeloid leukaemia. Drugs 67 (2), 299-320.

Nimmanapalli, R., Bali, P., O'Bryan, E., Fuino, L., Guo, F., Wu, J., Houghton, P., Bhalla, K., 2003. Arsenic trioxide inhibits translation of mRNA of bcr-abl, resulting in attenuation of Bcr-Abl levels and apoptosis of human leukemia cells. Cancer Res. 63 (22), 7950-7958.

Nowell, P.C., Hungerford, D.A., 1960. A minute chromosome in human chronic granulocytic leukemia. Science 132, 1497-1499.

O’Hare, T., Walters, D.K., Stoffregen, E.P., Jia, T., Manley, P.W., Mestan, J., CowanJacob, S.W., Lee, F.Y., Heinrich, M.C., Deininger, M.W., Druker, B.J., 2005. In vitro activity of Bcr-Abl inhibitors AMN107 and BMS-354825 against clinically relevant imatinib-resistant Abl kinase domain mutants. Cancer Res 65, 4500-4505.

Perri, M., Caroleo, M.C., Cione, E., 2016. Basic condition to formazan improves sensitivity of the MTT colorimetric assay dye. J. Bioanal. Tech. 1 (1). http:// dx.doi.org/10.16966/jbt.104.

Pignone, D., Sonnante, G., 2004. Wild artichokes of south Italy: did the story begin here? Genet. Res. Crop Evol. 51, 577-580.

Ramos, P.A., Guerra, A.R., Guerreiro, O., Freire, C.S., Silva, A.M., Duarte, M.F., Silvestre, A.J., 2013. Lipophilic extracts of Cynara cardunculus L. var. altilis (DC): a source of valuable bioactive terpenic compounds. J. Agric. Food Chem. 61 (35), 8420-8429.

Rowley, J.D., 1973. A new consistent chromosomal abnormality in chronic myelogenous leukemia identified by quinacrine fluorescence and Giemsa staining. Nature 243, 290-293.

Savage, D.G., Szydlo, R.M., Goldman, J.M., 1997. Clinical features at diagnosis in 430 patients with chronic myeloid leukemia seen at a referral center over a 16 -year period. Br. J. Haematol. 96, 111-116.

Shah, N.P., Tran, C., Lee, F.Y., Chen, P., Norris, D., Sawyers, C.L., 2004. Overriding imatinib resistance with a novel ABL kinase inhibitor. Science 305, 399-401.

Spiers, A.S., 1977. The clinical features of chronic granulocytic leukemia. Clin. Hematol. 6, 77-95.

Trela, E., Glowacki, S., Błasiak, J., 2014. Therapy of chronic myeloid leukemia: twilight of the imatinib era? ISRN Oncol. 2014, 596483. 